\title{
River Discharge Projection under Climate Change in the Chao Phraya River Basin, Thailand, Using the MRI-GCM3.1S Dataset
}

\author{
P. B. HUNUKUMBURA and Yasuto TACHIKAWA \\ Department of Civil and Earth Resources Engineering, Kyoto University, Kyoto, Japan
}

(Manuscript received 28 February 2011, in final form 9 September 2011)

\begin{abstract}
The impact of climate change on river flow in the Chao Phraya River basin in Thailand is analyzed by feeding future runoff projection data into a distributed flow routing model. The projection data used consists of daily runoff generation, which is downscaled into hourly data, by assuming the temporal pattern is proportional to GCM generated hourly precipitation. The GCM dataset used is a $20 \mathrm{~km}$ spatial resolution general circulation model (MRI-AGCM3.1S) developed by the Meteorological Research Institute, Japan Meteorological Agency, for the present climate experiment (1979-2003), the near future climate experiment (2015-2039), and the future climate experiment (2075-2099). The main findings of the river discharge projections are as follows: 1) clear changes in hourly flood peak discharge, daily drought discharge, and monthly discharge were detected; 2) for each discharge, the degree of change differed by location; 3) the changes appeared in the near future climate experiment and became clearer in the future climate experiment; and 4) a significant decrease in discharge was detected at the Pasak River basin in October.
\end{abstract}

\section{Introduction}

Global warming will have a serious impact on our future. Many scientists have already revealed that climate change is here to stay and will be irreversible for next thousand years, even if we drastically reduce the emission of greenhouse gases. The frequency and magnitude of floods, droughts, and sedimentation disasters are predicted to increase due to changes in precipitation extremes. The Intergovernmental Panel on Climate Change (IPCC), in its 4th assessment report (IPCC 2007a; IPCC 2007b), described the increase in global average surface temperatures and the potential increase of frequency of heavy rainfall, among other outcomes, based on long-term observations. The report also showed the projections of climate change according

Corresponding author: Yasuto Tachikawa, Department of Civil and Earth Resources Engineering, Kyoto University, C1-116, Kyoto University Katsura Campus, Nishikyo-ku, Kyoto 615-8540, Japan. E-mail: tachikawa@hywr.kuciv.kyoto-u.ac.jp (C) 2012, Meteorological Society of Japan to several greenhouse gas emission scenarios and the impacts of climate change on water-related disasters and water resources.

Projection of river discharge is necessary to cope with water-related disasters induced by climate change, such as floods, droughts, and water scarcity. In this regard, hydrologic and flow routing models play a major role in transferring the climate model outputs into river discharge. By using river discharge information, it is possible to assess future changes in water resources, flood discharge, droughts, etc., and especially possible future hotspots on water-related disasters can be identified. Hirabayashi et al. (2008) and Pokhret et al. (2010) analyzed changes in the future risks of floods and droughts on a global scale. They used a 1-degree spatial resolution runoff model with general circulation model (GCM) outputs. Although the 1-degree spatial resolution runoff model is sufficient for analyzing river discharge changes on a global scale, it is not adequate for analyzing changes at the regional or country scale. On the other hand, detailed, high-resolution hydrologic models have been used to analyze the impact of climate change 
at the basin scale (Kim et al. 2009; Kim et al. 2010; Kiem et al. 2008). Due to the high computational costs associated with hydrologic models and difficulties in identifying model parameters, it is hard to use such type of high resolution complex hydrologic models to identify the hotspots in the regional or country scale.

The purpose of this research is to find possible water-related hotspot basins under climate change on the regional/country scale by using a GCM runoff output and a flow routing model. We believe that two stages of research are necessary to analyze the impact of climate change on water resources. First, possible hotspot basins are identified on the regional/country scale, where significant change related to flood and water resources could occur under climate change scenarios. Then, a detailed hydrologic analysis is conducted for the hotspot basins with local information, and a detailed hydrologic model is designed, in order to create an accurate picture of possible water resource changes under climate change and, hence, to develop adaptive measures. This corresponds to the first stage of research. At this stage, the research target was to locate possible hotspot basins in large regions. Therefore, a computationally light model was suitable for long-term and spatially wide-range simulations, rather than a detailed simulation model. We have developed and applied a distributed flow routing model, which transforms the generated runoff by a GCM land surface model into river discharge at $1 \mathrm{~km}$ spatial resolution.

In this paper, we applied a distributed flow routing model for the Chao Phraya River basin in Thailand. Then, future river discharge was projected using the GCM (MRI-AGCM3.1S) output developed by the Meteorological Research Institute, Japan Meteorological Agency, to detect the hotspots on river discharge change. Clear changes in hourly flood peak discharge, daily drought discharge, and monthly discharge were detected. For each discharge, the degree of change differed according to location, and the changes appeared in the near future climate experiment, which became clearer in the future climate experiment.

In Section 2, a distributed flow routing model used for river discharge projection is described. In Section 3, future climate projection data generated by MRI-AGCM3.1S used for river discharge simulation is briefly explained. In Section 4, simulated river discharge projection in Thailand is discussed. Section 5 is the summary of the paper.

\section{Flow routing model}

\subsection{Catchment model}

A catchment model was developed using a digital elevation model, DEM. The flow direction of the catchment was modeled using the 8-direction method (Jensen and Domingue 1988), which assumes the flow direction 1-dimensionally to the steepest gradient direction as illustrated in Fig. 1. Each slope or channel unit, determined by the flow direction, was represented by a rectangle formed by the two adjacent nodes of the DEM. The topographical data used here were the 30 arc-second DEM and flow direction stored in HydroSHED (USGS 2011) for Asian regions. The spatial resolution of the topographic data was about $1 \mathrm{~km}$. The catchment model was constructed as a network of these rectangles. Each rectangular unit was used for the element of runoff or channel flow simulation.

\subsection{Flow model}

The kinematic wave model was applied to all rectangular units shown in Fig. 1, to route the water downstream according to the flow direction information, which transformed the runoff generation by a GCM land surface model into river discharge. The continuity equation for each rectangular unit is:

$$
\frac{\partial A}{\partial t}+\frac{\partial Q}{\partial x}=q(t)
$$

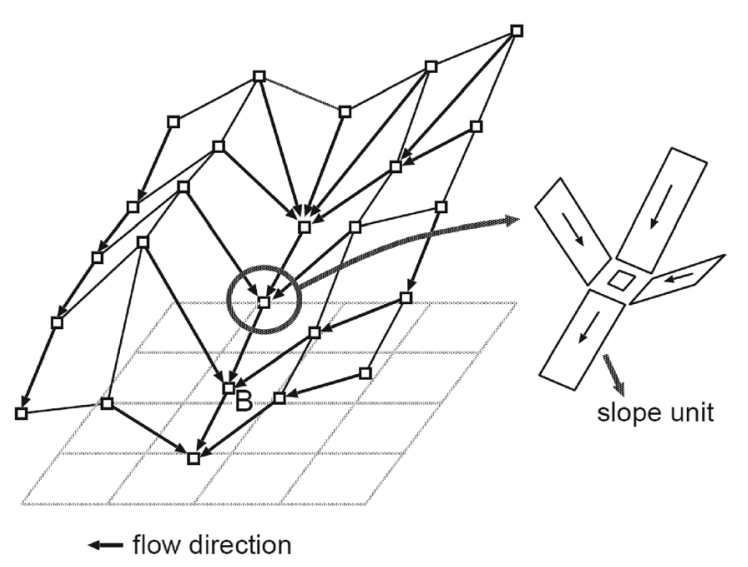

Fig. 1. Schematic drawing of a catchment model using a DEM. The arrow in the figure shows the flow of discharge $Q$ on the slope or river unit. The runoff generation is provided to each unit as lateral inflow $q$. 
where $t$ is time; $x$ is the distance from the top of the rectangular unit; $A$ is cross-sectional area on the rectangular unit; $Q$ is discharge; and $q(t)$ is the lateral inflow per unit length of slope or channel unit given as runoff generation simulated by the land surface model ( $\mathrm{SiB}$ model) embedded in the MRIAGCM3.1S. The Manning type relation of the discharge to the cross-sectional area:

$$
Q=\alpha A^{m}, \quad \alpha=\frac{\sqrt{i_{0}}}{n}\left(\frac{1}{B}\right)^{m-1}, \quad m=5 / 3,
$$

was used as a momentum equation to route the water; where $i_{0}$ is slope; $n$ is the Manning roughness coefficient; and $B$ is the width of the flow. The slope $i_{0}$ was determined according to the topographical data.

The model parameters of the flow model were $B$ and $n$. The value of $B$ was determined using the regression relationship $B=a S^{c}$; where $S$ is the catchment area at the points, and $a=1.06$ and $c=0.69$ are constant parameters. The value of $n$ was determined to be $0.03 \mathrm{~m}^{-1 / 3} \mathrm{~s}$ and $11.0 \mathrm{~m}^{-1 / 3} \mathrm{~s}$ respectively for channel and slope flow. Here, we assumed that river flow is dominant when the number of the grids of the upper part is larger than 250 (about $250 \mathrm{~km}^{2}$ ), and slope flow is dominant when the number of grids is smaller than 250. These values were used in reference to other applications (Tachikawa et al. 2011). Tachikawa et al. (2011) determined the values of these model parameters to fit the flow simulation results by the distributed flow routing model to that of a distributed hydrologic model tuned by the observed data at 2 typical Japanese catchments. The important model parameter which controls the flow routing is the Manning roughness coefficient $n$. To identify possible hotspot basins in the regional/country scale, identification of the value to reproduce the precise local discharge is unnecessary. Therefore, we used the values determined at Japanese catchments, which fell in the proper range. Hereafter, we refer to the $1-\mathrm{km}$ distributed flow routing model as $1 \mathrm{~K}$ FRM (http://hywr.kuciv.kyoto-u.ac.jp/products/ 1K-DHM/1K-DHM.html).

\section{GCM data used for river flow projection}

The input data for river discharge projection was provided by the general circulation model (MRIAGCM3.1S), with about $20 \mathrm{~km}$ spatial resolution developed by the Meteorological Research Institute in Japan (Kitoh et al. 2009; Kusunoki et al. 2011). The products of MRI-AGCM3.1S consisted of various atmospheric and hydrologic variables for the present climate experiment (1979-2003), the near future climate experiment (2015-2039), and the future climate experiment (2075-2099), which were simulated under the SRES A1B scenario.

The river discharge was calculated by feeding the GCM projection runoff data into $1 \mathrm{~K}-\mathrm{FRM}$. The hydrologic projection variables related to river discharge are shown in Fig. 2. The input data to the flow model of $1 \mathrm{~K}-\mathrm{FRM}$ were daily surface runoff generation and daily sub-surface runoff generation data, which were simulated by a land-surface

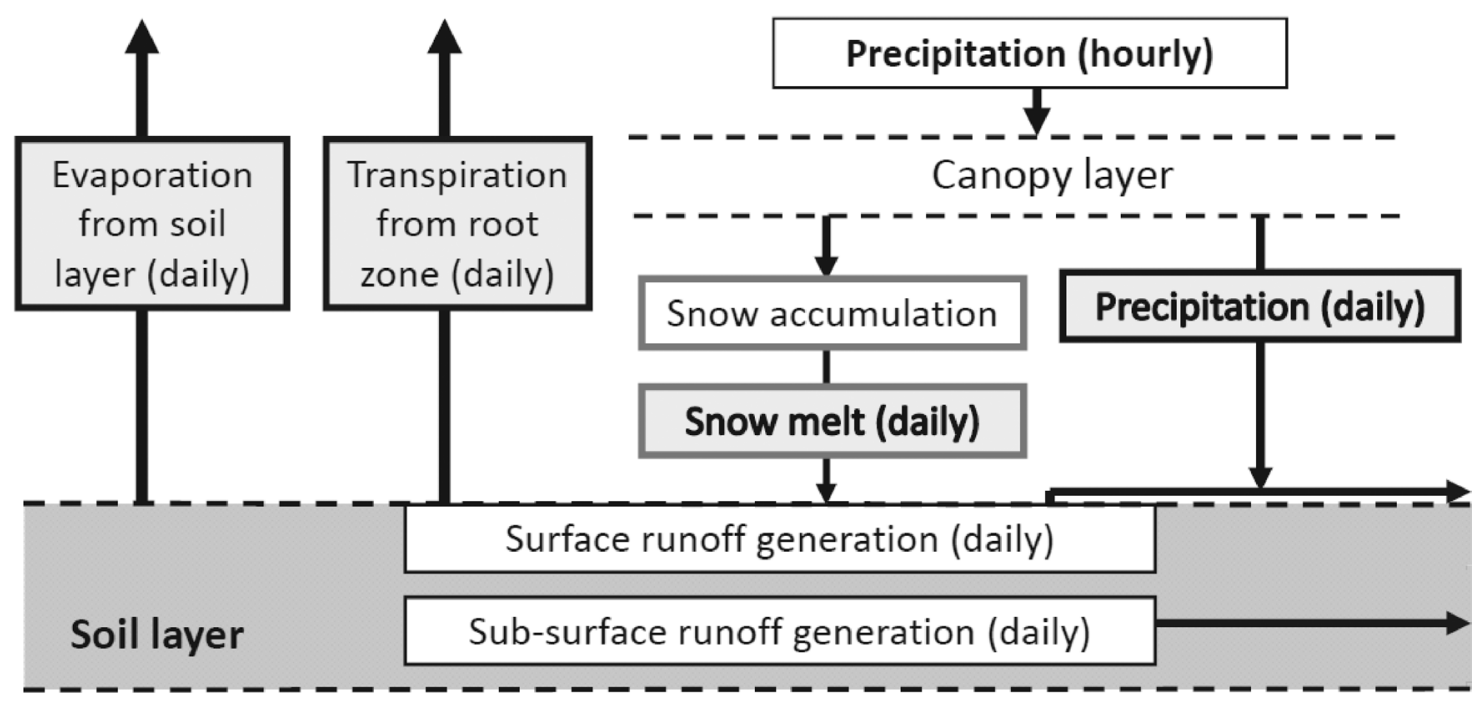

Fig. 2. Land surface generation data of MRI-AGCM3.1S fed into river discharge simulation. 
process model ( $\mathrm{SiB}$ Model) embedded in the MRIAGCM3.1S. Tachikawa et al. (2011) compared the simulated discharge of the 1K-FRM driven by the GCM runoff generation data with reference discharge data, which were developed using a distributed hydrologic model driven by the GCM hourly precipitation, daily snow melting, and daily evapotranspiration data. They found the r.m.s. value of the difference of the simulated discharges to have been less than $50 \mathrm{~m}^{3} \mathrm{~s}^{-1}$ at the Yoshino River basin $\left(2740 \mathrm{~km}^{2}\right)$ in Japan when the daily input of surface runoff generation into the $1 \mathrm{~K}-\mathrm{FRM}$ was downscaled to hourly data. Thus, they temporally downscaled the daily surface runoff generation data $q_{d}$ to hourly value $q_{i}$ using the hourly precipitation on canopy layer $P_{c, i}$ in the MRI-AGCM3.1S as

$$
q_{i}=\left(P_{c, i} / \sum_{j=1}^{24} P_{c, j}\right) q_{d}, \quad i=1, \ldots, 24,
$$

where $i$ represents the index for hourly data. Then, adding the daily mean intensity of the sub-surface runoff generation to the hourly intensity of the surface runoff generation, it was given to $1 \mathrm{~K}-\mathrm{FRM}$. In this study, we also used the temporally downscaled hourly surface and sub-surface runoff generation data as the input lateral flow to the $1 \mathrm{~K}-\mathrm{FRM}$ model to transform the runoff generation into river discharge.

\section{Impact of climate change on river discharge in the Chao Phraya River basin}

We selected the Chao Phraya River basin which, with an area of about $160400 \mathrm{~km}^{2}$, is the largest river basin in Thailand to analyze the impact of climate change on river discharge. The basin covers approximately one third of the total territory of Thailand and is very important to agricultural and economic activities. However, to the authors' knowledge, no studies have been carried out thus far on probable changes to future river discharge in this basin using high spatial resolution. Therefore, in this study, we have generated runoff simulations for 75 years for the present climate experiment (1979-2003), the near future climate experiment (2015-2039), and the future climate experiment (2075-2099). Runoff simulation data of hourly maximum and daily mean were stored for each day, with about $1 \mathrm{~km}$ spatial resolution. The simulated discharge data were analyzed to assess changes to the flood risk and water resources.

\subsection{Change of flood risk}

Annual maximum hourly discharge data were compiled, and the statistical characteristics were analyzed. Figure 3 shows the change ratio of the mean of the annual maximum hourly discharge for the near future climate experiment (a) and the future climate experiment (b), with respect to the present climate experiment. Generally, the mean annual maximum hourly discharge of the main stream of the Chao Phraya River did not change significantly in both near future and in future experiments; however, that of the tributaries changed from location to location. Notably, the mean of the annual maximum hourly discharge of some tributaries in the north-central and the southwestern part of the basin showed an increasing trend in near future experiments, and this trend was clearly visible in the future climate experiments. The ratio of the standard deviation of the annual maximum hourly discharge for the near future climate experiment (a) and the future climate experiment (b) with respect to the present climate experiment are shown in Fig. 4. The standard deviation also showed an increasing trend, especially in the north-central and southwestern tributaries, and, therefore, an increase in the T-year return period flood in the near future and the future climate is expected in these basins.

The Gumbel distribution was fitted to the annual maximum hourly discharge at each location for each climate experiment; then, the 10-year return period discharge was obtained for each climate independently. The SLSC (standard least-square criterion; Takara and Stedinger 1994) was used to evaluate the goodness-of-fit of the distribution, and most of the tributaries showed good agreement. The SLSC values for each climate experiment were less than 0.05 (Fig. 5). Figure 6 shows the change ratio of the 10-year return period for the annual maximum hourly discharge in the near future climate experiment (a) and the change ratio in the future climate experiment (b) with respect to the present climate experiment. The spatial pattern is similar to the change of the mean of the annual maximum hourly river discharge. It is important to recognize that the change of the discharge would appear in particular at the tributaries and that the changes become clearer in the future climate experiment.

Simulated discharge at each major tributary (shown in Fig. 7) was further analyzed to understand the changes. Table 1 shows the change ratio of the 10-year annual maximum hourly discharge 

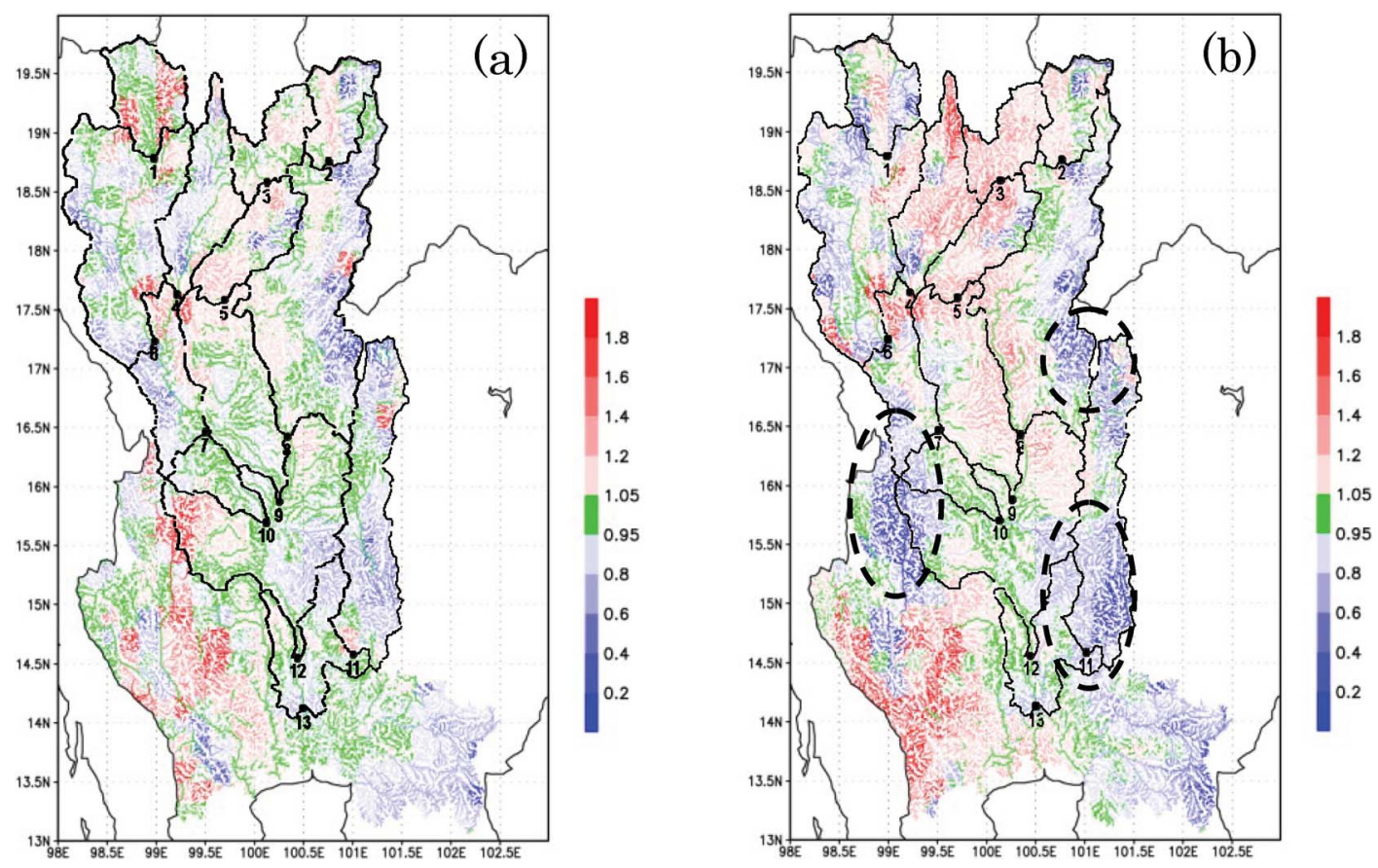

Fig. 3. The change ratio of the mean of the annual maximum hourly discharge for the near future climate experiment to the present climate experiment (a), and the future climate experiment to the present climate experiment (b).
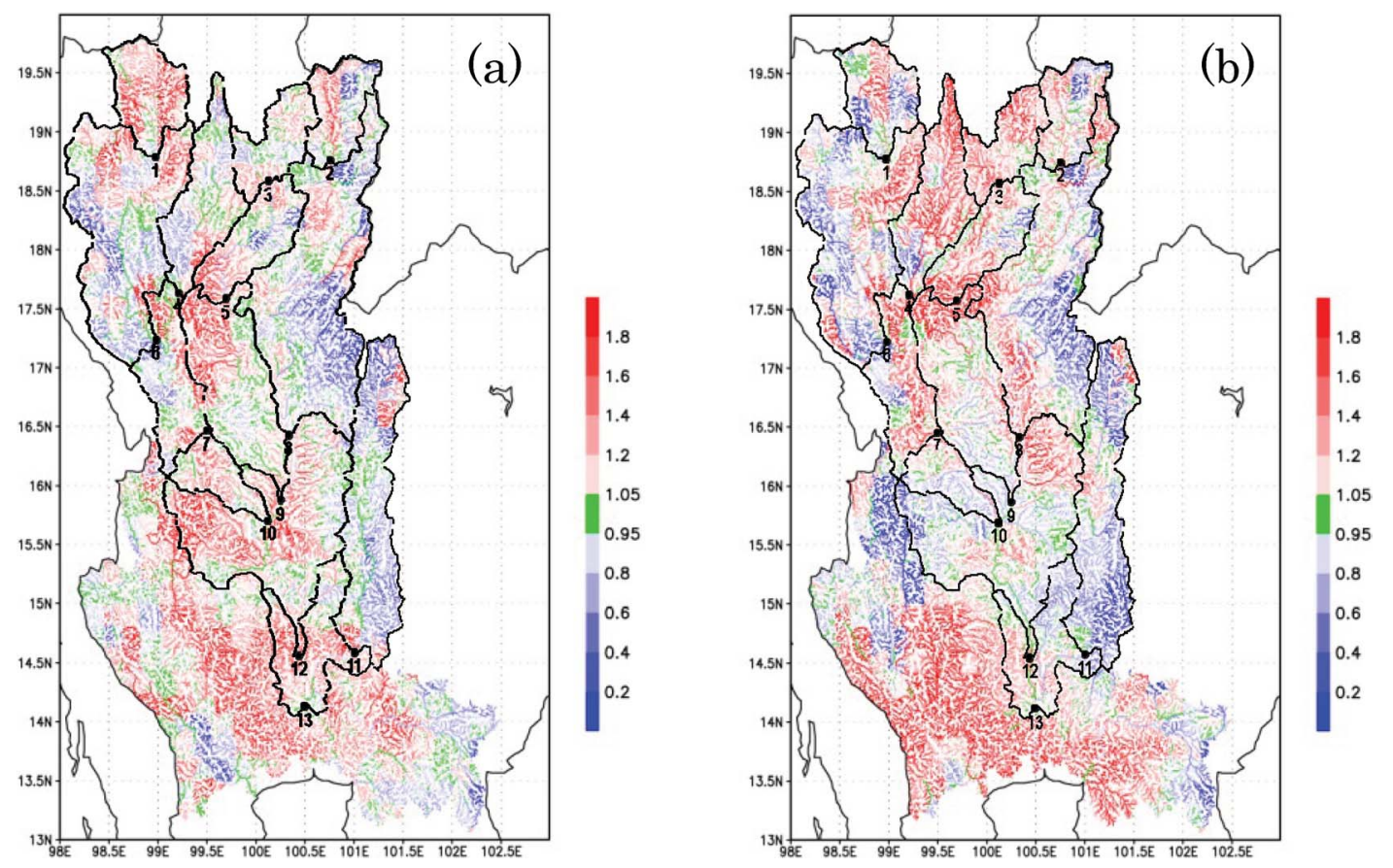

Fig. 4. The change ratio of the standard deviation of the annual maximum hourly discharge for the near future climate to the present climate experiment (a), and the future climate to the present climate experiment (b). 


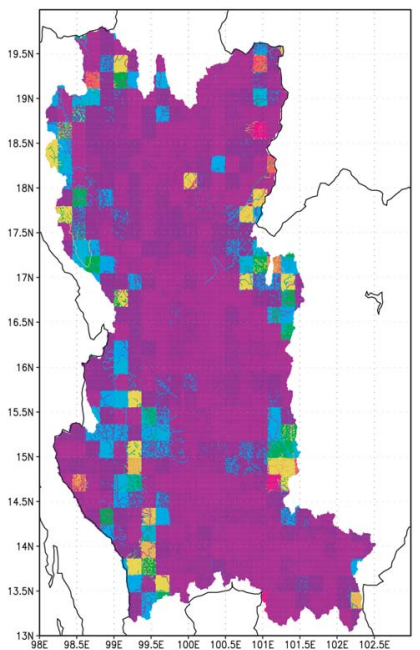

(a) Present Climate

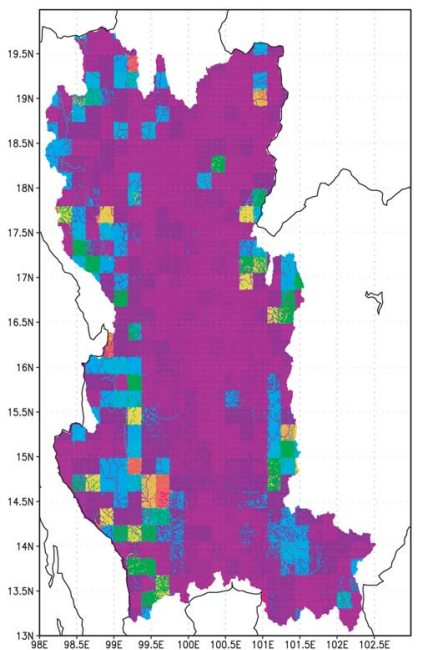

(b) Near Future Climate

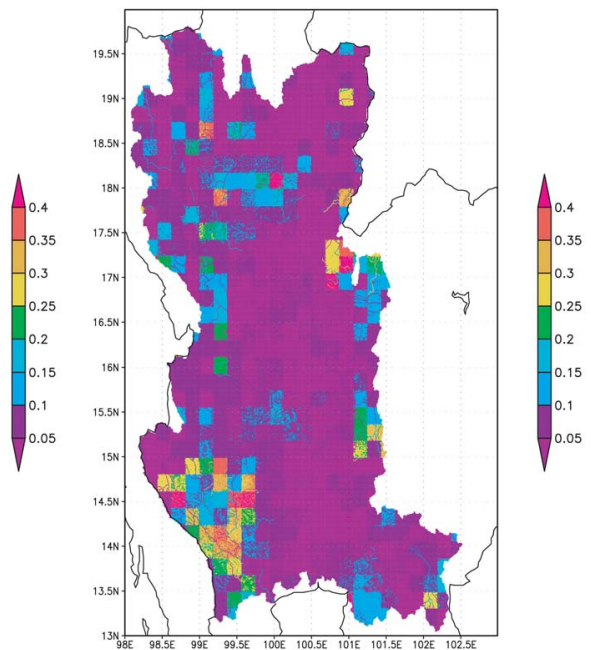

(c) Future Climate

Fig. 5. Values of SLSC for fitting the Gumbel distribution to the annual maximum hourly discharge for each experiment.
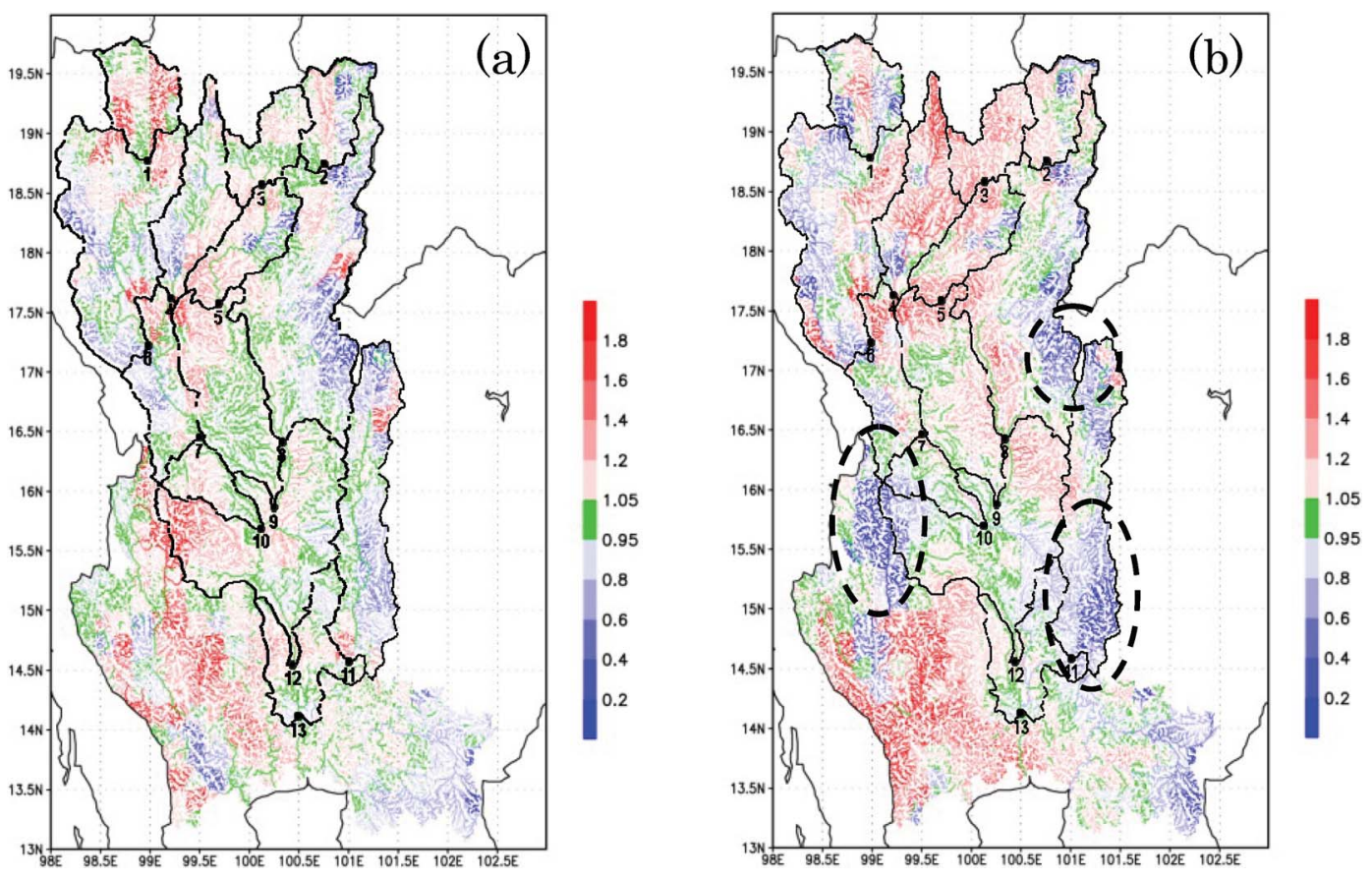

Fig. 6. The change ratio of the 10-year annual maximum hourly discharge for the near future climate to the present climate experiment (a), and the future climate to the present climate experiment (b).

at each station for the near future and the future climate experiments, with respect to the present climate experiment. The 10 -year annual maximum hourly discharge of the upstream tributary of the
Nan River (station number 2) in the near future climate with respect to the present climate represents the highest percentage increase (of 35\%) among all other stations, while that of the Pasak 


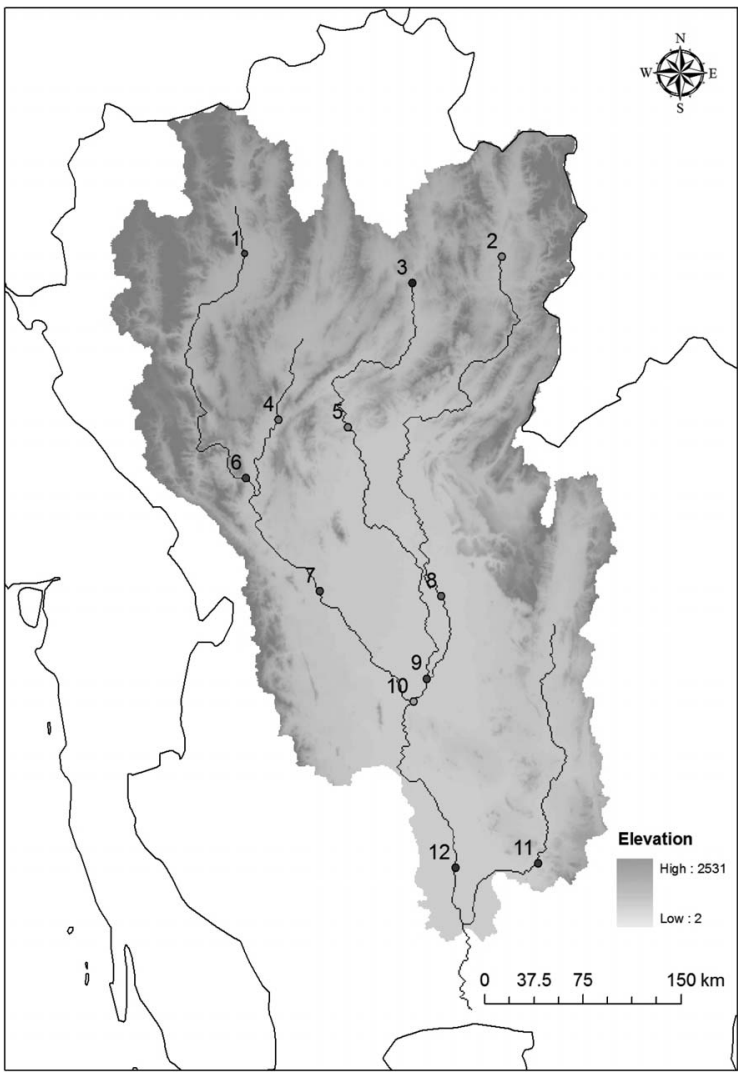

Fig. 7. The Chao Phraya basin and its main tributaries.

River (station number 11) represents a 5\% decrease in the near future climate. All other stations showed increases of $0.0 \%$ to $8 \%$ in the near future climate with respect to the present climate. The future climate experiment clearly indicated an increasing trend in the 10-year annual maximum hourly discharge in many tributaries (station numbers 1, 2, 3, $4,5,6,7,9,10,12)$, with respect to the present climate. Notably, the percentage increase was higher than $15 \%$ for most of the stations. In contrast, the Pasak River (station number 11) showed a decreasing trend, with a decrease of $23 \%$ in the future climate experiment.

Figure 8 shows the percentage difference of the mean of annual maximum hourly rainfall intensity for the near future climate (a) and the future climate (b) with respect to the present climate. Generally, the rainfall intensity tended to increase in the near future climate, and the increase was clearly visible in all areas of the Chao Phraya River basin
Table 1. The change ratio of the 10-year annual maximum hourly discharge at major tributaries.

\begin{tabular}{lcc}
\hline & \multicolumn{2}{c}{$\begin{array}{c}\text { The change ratio of the 10-year } \\
\text { annual maximum hourly discharge }\end{array}$} \\
\cline { 2 - 3 } Station ID & Near Future/Present & Future/Present \\
\hline 1 & 1.06 & 1.23 \\
2 & 1.35 & 1.19 \\
3 & 1.01 & 1.23 \\
4 & 1.03 & 1.55 \\
5 & 1.04 & 1.28 \\
6 & 1.01 & 1.09 \\
7 & 1.00 & 1.22 \\
8 & 1.00 & 0.97 \\
9 & 1.08 & 1.18 \\
10 & 1.03 & 1.05 \\
11 & 0.95 & 0.77 \\
12 & 1.05 & 1.03 \\
\hline
\end{tabular}

in the future climate experiment. Therefore, it can be noted that the increase of rainfall intensity and the steep topography would be the primary possible reasons for an increasing trend in the annual maximum hourly discharge at upstream mountainous tributaries of the Chao Phraya River basin. However, simply examining the changes in rainfall intensity over the basin cannot provide a clear picture of the changes in peak discharge, especially for dry basins. In such basins, even high rainfall intensity events may not produce high peak flow if the initial status of the basin is comparatively dry and with high recharge capacity. The hourly rainfall intensity indicated an increasing trend all over the Chao Phraya River basin; however, the mean of the maximum hourly discharge and 10-year annual maximum hourly discharge showed a significant decrease in some western parts, as well as in the eastern part of the basin (see the circled areas of Fig. $3 b$ and Fig. 6b).

To estimate dry basins, the mean annual potential evapotranspiration was calculated using the Hargreaves temperature based equation (Hargreaves and Samani 1985; Shuttleworth 1993). Figure 9 shows the changes in the mean annual precipitation and the mean annual potential evapotranspiration. The Hargreaves method, which demands only temperature data, showed reasonable potential evapotranspiration estimations with global validity (Allen et al. 1998). Estimated evapotranspiration using this model for five days or more at irrigated sites was found to compare favorably with that of the 


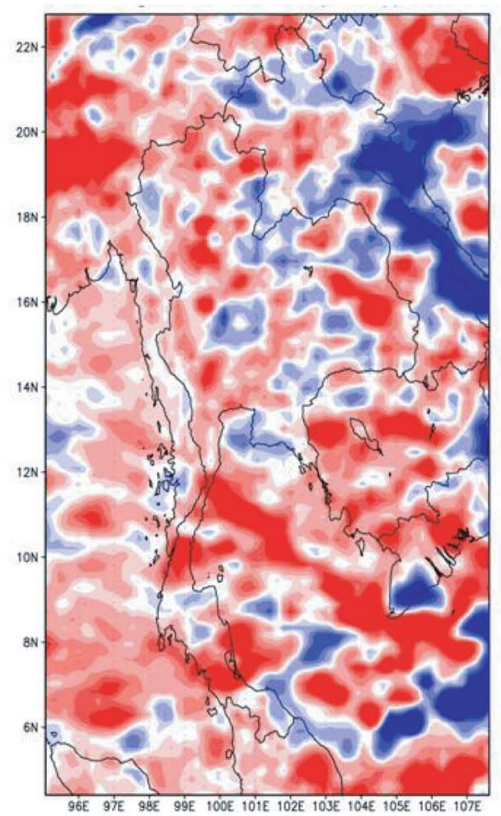

(a) Near Future

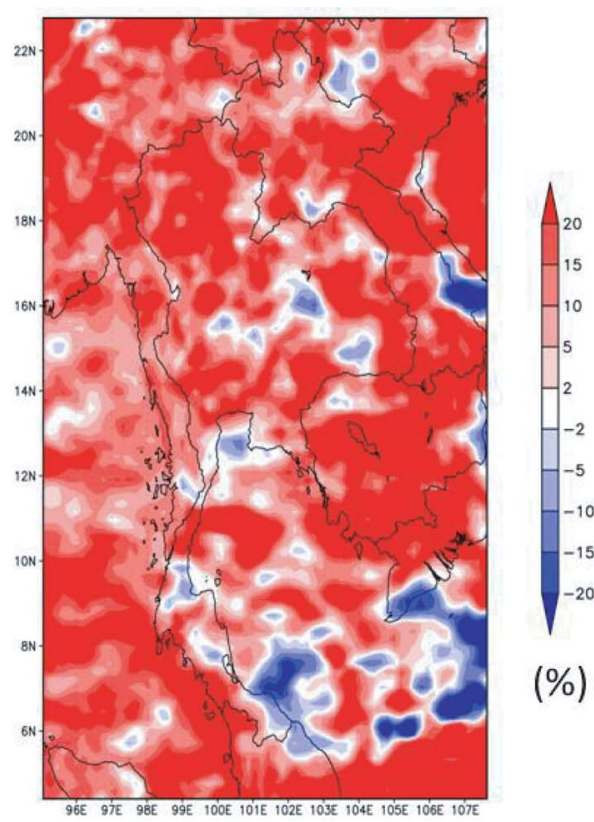

(b) Future

Fig. 8. Percentage difference of the mean of the annual maximum hourly rainfall intensity in Thailand for the near future climate to the present climate experiment (a), and the future climate to the present climate experiment (b).

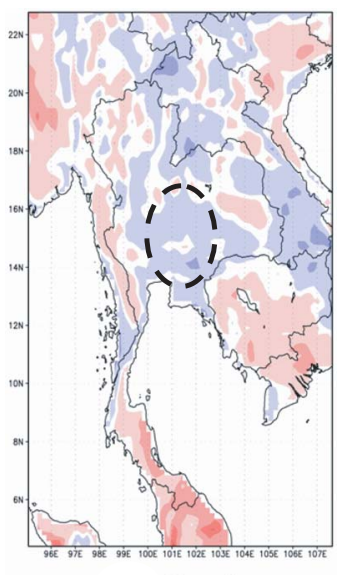

Near Future

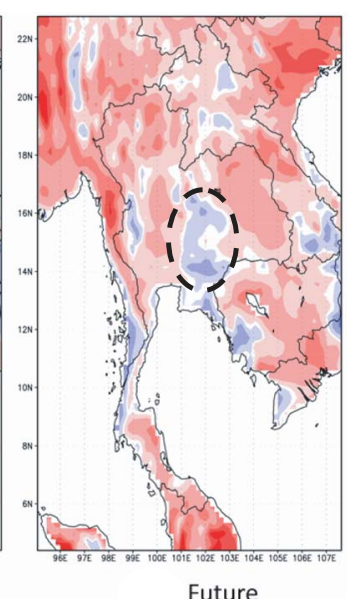

(a)
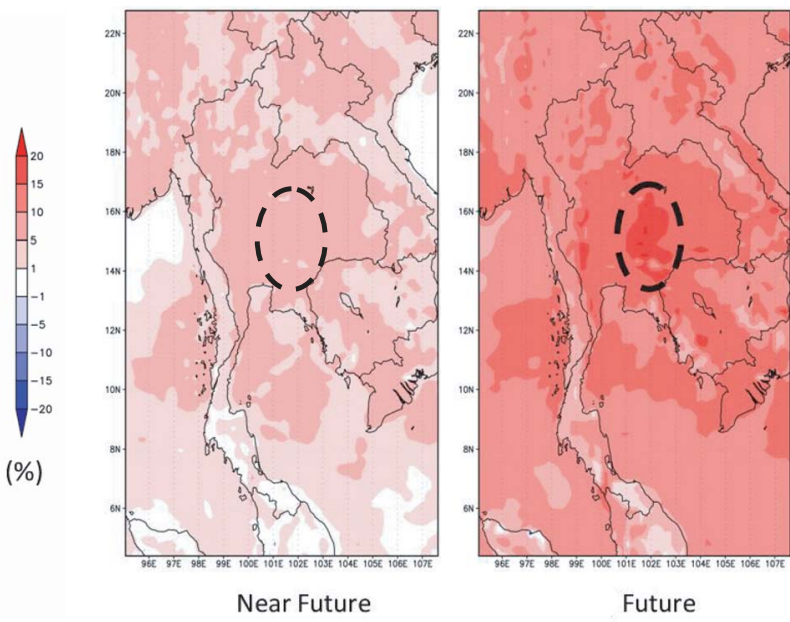

\begin{tabular}{l}
10 \\
0 \\
$:$ \\
$\vdots$ \\
\hdashline \\
-1 \\
-2 \\
$(\%)$
\end{tabular}

(b)

Fig. 9. Percentage difference of the mean annual precipitation (a) and potential evapotranspiration (b) in the near future and the future climate experiment with respect to the present climate experiment. The area designated by the circle corresponds to the Pasak River basin area. 
detail models, such as the FAO Penman-Monteith model (Hargreaves and Allen 2003). The Hargreaves temperature-based equation is recommended for data-sparse areas, and the equation is shown below:

$$
E T_{0}=0.0023 S_{0}\left(T_{\max }-T_{\min }\right)^{0.5}(T+17.8),
$$

where $E T_{0}, T_{\max }, T_{\min }, T$, and $S_{0}$ are potential evapotranspiration $\left(\mathrm{mm} \mathrm{day}^{-1}\right)$, mean monthly maximum temperature $(\mathrm{C})$, mean monthly minimum temperature $(\mathrm{C})$, average daily temperature (C), and water equivalent of extraterrestrial radiation $\left(\mathrm{mm} \mathrm{day}^{-1}\right)$, respectively. As shown in Fig. 9, we clearly observe that the mean annual precipitation tends to decrease significantly, while the potential evapotranspiration tends to increase in the circled areas of the figure. The rate of increase of the potential evapotranspiration may not be the same as the rate of increase of actual evapotranspiration in dry basins, as the soil moisture controls the latter. However, we can expect the circled areas in Fig. 9 to be a comparatively dry area, which corresponds to the areas with decreasing trend of the hourly peak discharge shown in Fig. 3b and Fig. 6b.

\subsection{Change of drought risk}

Daily mean simulated discharge data were compiled and used to analyze changes in water resources in the basin. Figure 10 shows the change ratio of the mean rainy season (May to October) discharge in the near future climate experiment (a) and the change ratio in the future climate experiment (b) with respect to the present climate experiment. The mean rainy season river discharge of many tributaries and the main streams showed a decreasing trend in the near future climate. In the future climate experiment, the mean rainy season discharge of the main streams showed less change compared with the present climate. However, a decrease trend of the mean rainy season flow in small tributaries became clearer in the future climate experiment.

The change ratio of the mean dry season (November to April) discharge for the near future climate experiment (a) and the future climate experiment (b) with respect to the present climate experiment is shown in Fig. 11. It is clearly observed that the mean dry season flow tended to decrease in the near future experiment throughout the basin, and this may cause water shortages in many parts of the basin. In the future climate experiment, the mean dry season discharge in the western tributa- ries tended to decrease further. In contrast, mean dry season flow is likely to increase in the northcentral part of the basin, and this causes the change ratio to remain within $-5 \%$ to $5 \%$ in most of the major streams in the future climate experiment. When we compare the water resource in the near future and future climate experiment, it can be observed that the water resource in the near future climate is more vulnerable in many parts of the basin than in the future climate experiment. However, significant reduction of stream flow can be observed in some areas in the western part and in the eastern part of the basin in the future climate as well (see the circled area in Fig. 10 and Fig. 11). The main reason for this pattern is that the mean annual precipitation tends to decrease significantly, adding the increase of potential evapotranspiration (circled area of Fig. 9).

Figure 12 compares the mean monthly discharge at selected locations in Fig. 7 for the present, near future, and future climate experiments. According to the figure, mean July flow seemed to decrease significantly at many major tributaries (stations 1 , $4,5,6,7,8,9,10,12)$ in the near future, as well as in the future climate experiments. This is a very important observation, as this period is the early stage of the paddy cultivation, which requires much water. However, the mean annual discharge did not change significantly in many major tributaries, except at the Pasak River (station number 11). In the Pasak River basin, the mean September and October discharges decreased significantly in the near future climate experiment and further decreased in the future climate experiment. Moreover, mean annual precipitation tended to decrease in this basin, while the mean potential evapotranspiration tended to increase (see the circled area of Fig. 9). Therefore, when possible future water resource scarcity is a concern, the Pasak River basin can clearly be identified as a hotspot, and more detailed studies should be carried out which consider both changes in water resources and the water demand.

A global scale analysis carried out by Doll and Zhang (2010) showed that the monthly low flows tended to decrease over Thailand in the future climate under both A2 and B2 climate change scenarios. However, it was difficult get a clear picture of the changes in major streams of the Chao Phraya basin due to the coarse spatial resolution of this global study. Therefore, in this study, flow duration curves (FDCs) for each climate experiment of 25 years at each location were developed using 25 

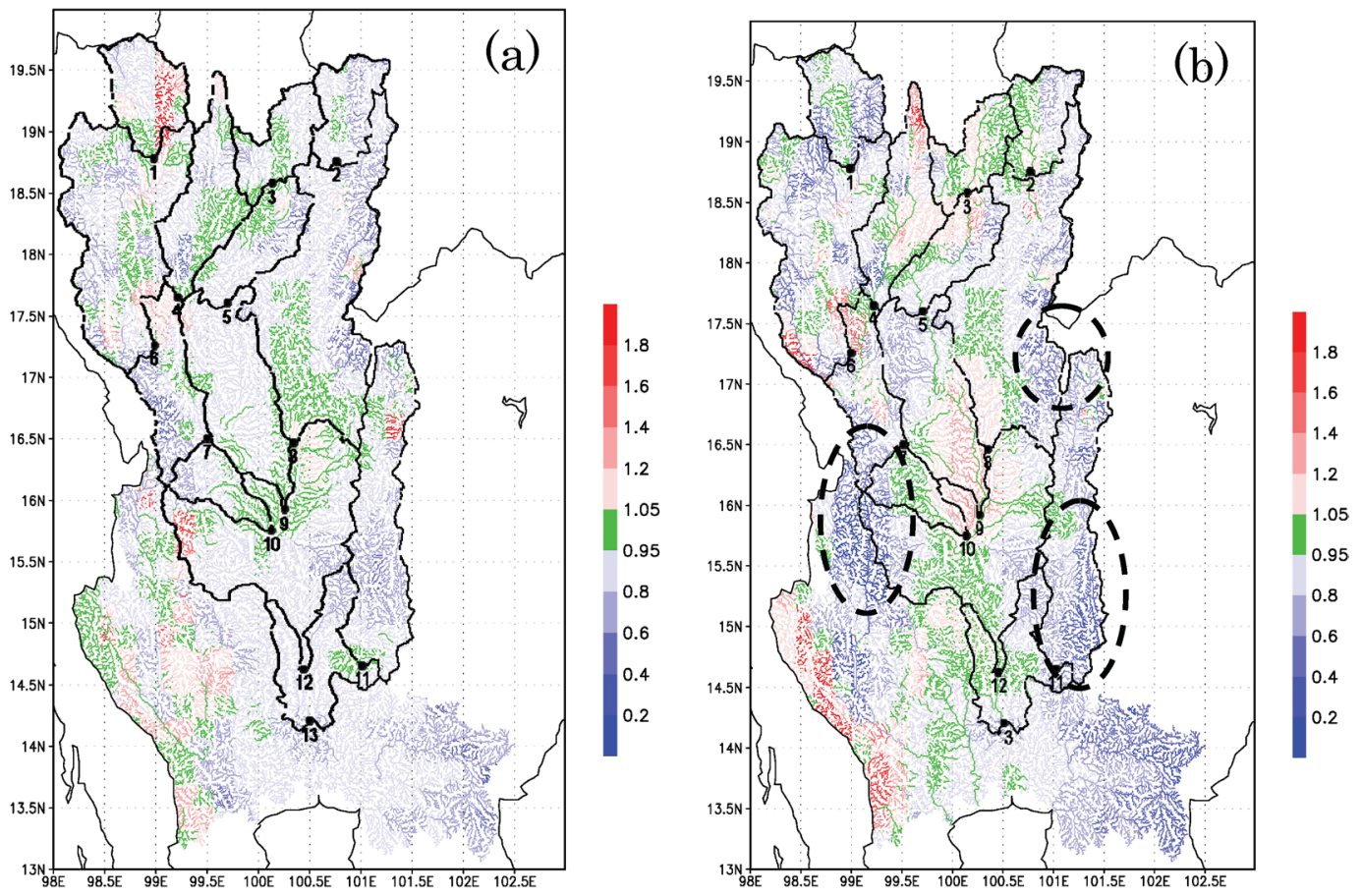

Fig. 10. The change ratio of the mean rainy season (May to October) discharge for the near future climate to the present climate experiment (a), and the future climate to the present climate experiment (b).
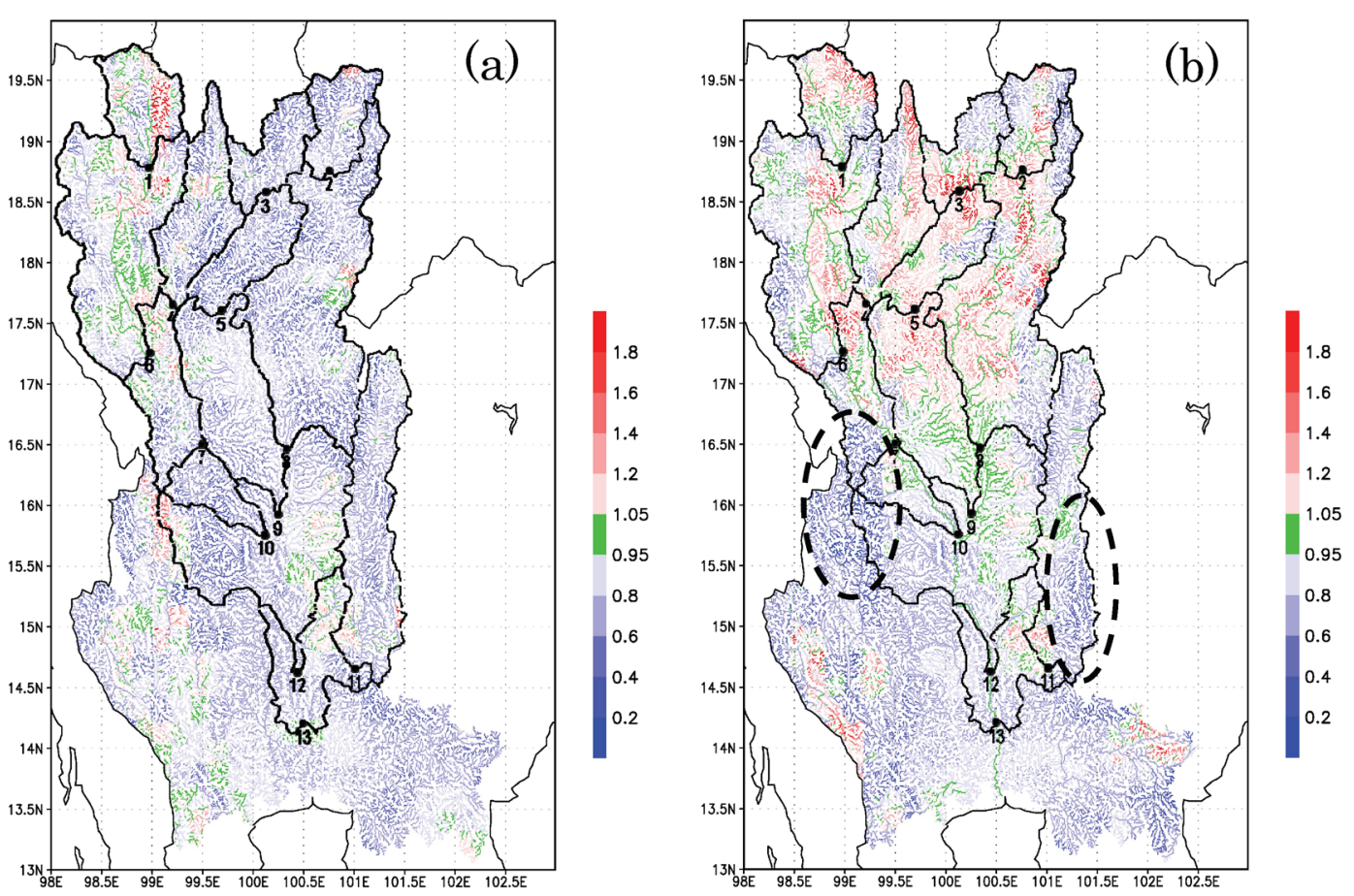

Fig. 11. The change ratio of the mean dry season (November to April) discharge for the near future climate to the present climate experiment (a), and the future climate to the present climate experiment (b). 

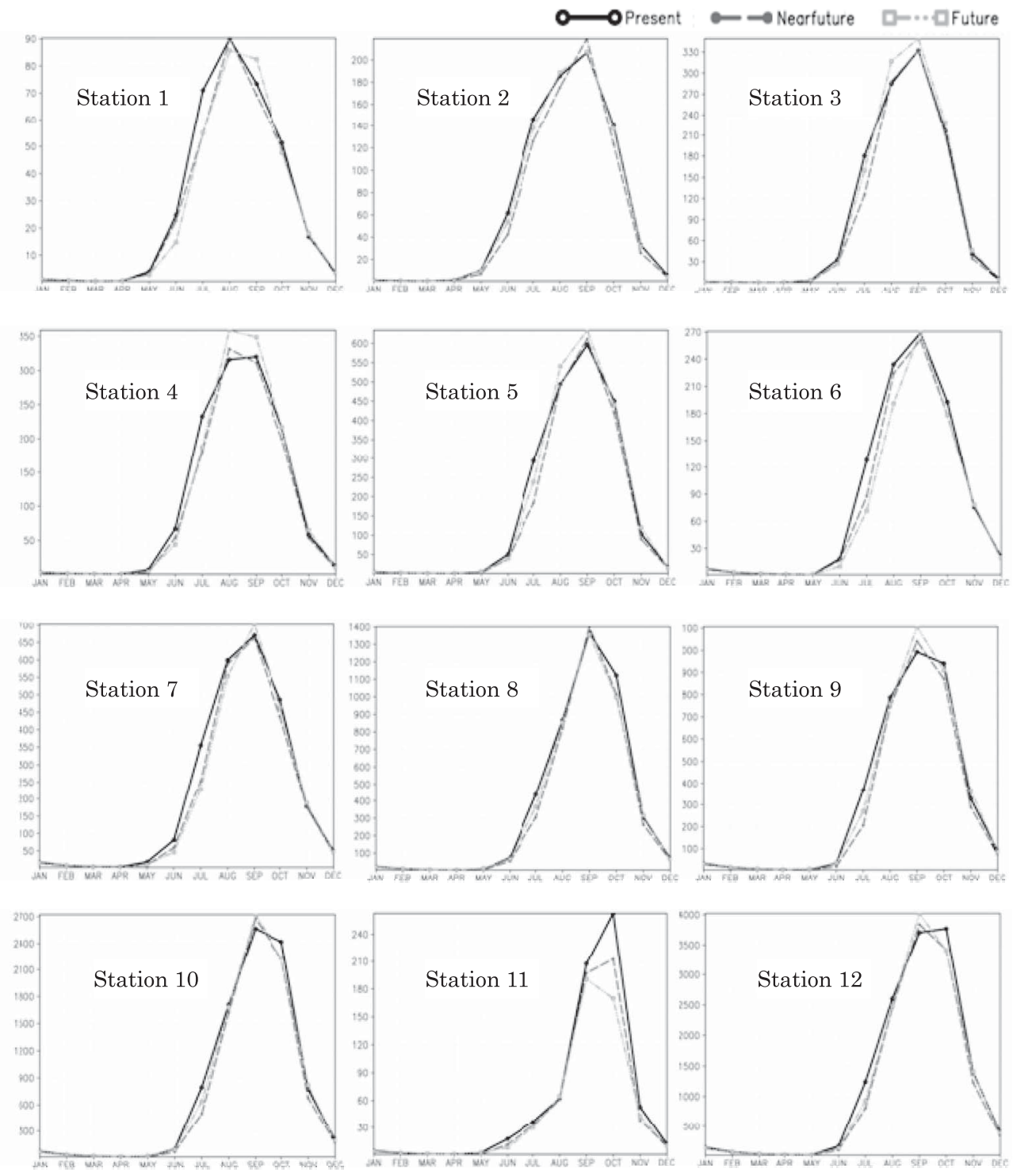

Fig. 12. The mean monthly discharge at selected locations of major tributaries for the present, near future, and future climate experiments.

years of mean daily discharge simulations to analyze changes in the low flows of the basin. Figure 13 compares the low flow section (flows having the exceedance probability of $90 \%$ or greater) of the FDCs at each location for the present, near future, and future climate experiments. It is clearly observed that the low flow values at all major tributaries tended to decrease significantly in the near future and future climate experiments, and this will increase the drought risk in the basin.

\section{Summary}

The impact of climate change on river discharge regimes in the Chao Phraya basin, Thailand, was analyzed by feeding future runoff projection data into a distributed flow routing model, 1K-FRM. Spatially distributed river discharge was simulated with the kinematic wave flow model according to the catchment model with $1 \mathrm{~km}$ spatial resolution. The future climate projection information used 

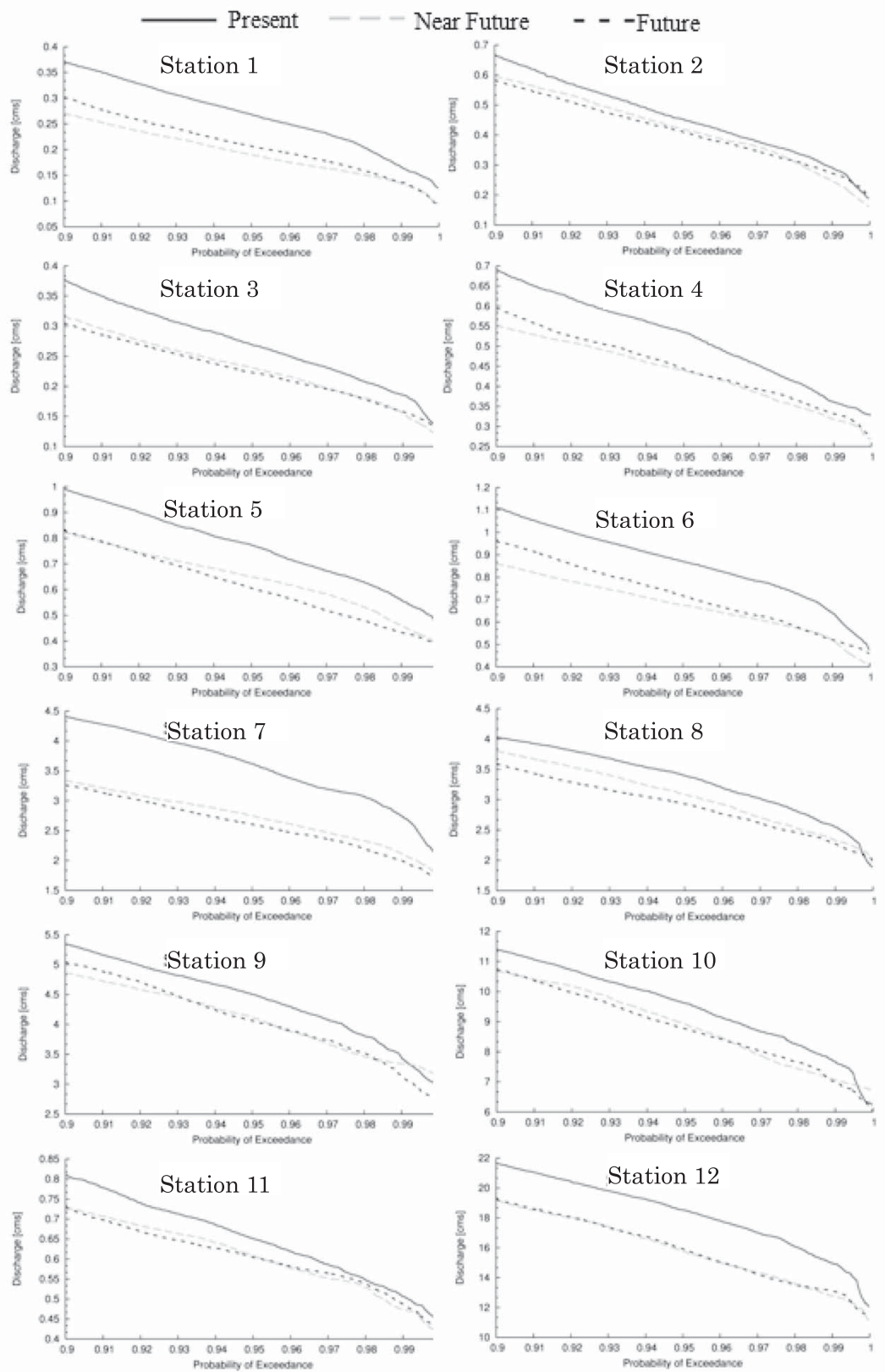

Fig. 13. Flow duration curves at the low-flow section (flows having the exceedance probability of $90 \%$ or greater), at selected locations of major tributaries for the present, near future, and future climate experiments.

for the river discharge simulation was GCM generated daily surface runoff generation data, temporarily downscaled by hourly canopy precipitation and daily subsurface runoff generation data. The projection data consisted of three numerical climate experiments: the present climate experiment (1979-2003), the near future climate experiment (2015-2039), and the future climate experiment (2075-2099), which were simulated under the SRES A1B scenario using a $20 \mathrm{~km}$ spatial resolution general circulation model (MRIAGCM3.1S) developed by the Meteorological Research Institute, Japan Meteorological Agency. Using the projection data, 75 years of river discharge simulations were conducted, and the results were statistically analyzed. 
At the north-central and the southwestern tributaries of the Chao Phraya basin, Thailand, the mean annual maximum hourly discharge, as well as 10-year return period flood discharge, tended to increase in the near future experiment. Moreover, the increase was much clearer in the future experiment and is expected to lead to increased flood risk in those tributaries. Furthermore, the 10-year return period flood discharge at most of the major tributaries, with the exception of the Pasak River, showed an increasing trend in the near future experiment. Notably, for seven major tributaries (1, 2, 3, 4, 5, 7, and 9 in Fig. 7 and Table 1) in the future experiment, the 10 -year return period flood discharge is above $18 \%$ with respect to the present climate experiment. A recent study on changes of the extreme river discharge at the global scale also showed that the frequency of floods over the entire country of Thailand tended to increase significantly in the future climate (Hirabayashi et al. 2008). Moreover, the Chao Phraya basin was found to be one of the most affected flood prone basins in Thailand in the near future and future climate (Koontanakulvong and Chaowiwat 2011). In contrast, we found that the flood risk at the Pasak River tended to decrease in the near future and further decrease in the future climate experiment. Therefore, high spatial resolution discharge simulations are vital to identify the hotspots at the regional/country scale.

When we considered the changes in the water resources of the basin, both the rainy season mean discharge and the dry season mean discharge showed a decreasing trend in most of the small tributaries and major streams for the near future experiment. This may lead to increased risk of a water shortage in the basin. In the future climate experiment, the mean rainy season, as well as the dry season discharge, showed a clear decreasing trend in most of the small tributaries; however, for most of the major streams, this lay within a $-5 \%$ to $5 \%$ change, with respect to the present climate. It is clearly noted that the water resources in the Pasak River tended to decrease in the near future climate and further decreased in the future climate experiment.

Through the 75 years of runoff simulations in the Chao Phraya River basin, the entire findings were summarized as follows: 1) a clear change of temporal and spatial discharge patterns appeared; 2) the degree of the change differed according to location; and 3) the changes appeared in the near future climate experiment, which became clearer in the future climate experiment, as shown in Figs. 3 and 4. The regional flow change characteristics were observed as follows: 4) the flood risks tended to increase in the north-central and southwestern small tributaries and most of the major streams, as shown in the increase of the 10-year annual maximum hourly discharge in Fig. 6; 5) mean July flow showed a decreasing trend in many major tributaries as shown in Fig. 12;6) low flow values at all major tributaries tended to decrease and led to increased drought risk, as shown in Fig. 13; and 7) the Pasak River basin can be clearly identified as a hotspot when the scarcity of water resources is as shown in Fig. 12 and Table 1.

A detailed hydrologic research for the hotspot basin which considers both the availability of water resources and the demand change in the basin is a next step. Additionally, we are concerned that the river discharge projection was conducted only using one GCM output with a single future scenario. Analysis of the uncertainty of the discharge projections would be a further study to analyze flood and drought risks and develop adaptive measures.

\section{Acknowledgments}

This work was conducted under the framework of "Projection of the change in future weather extremes using super-high-resolution atmospheric models," supported by the KAKUSHIN Program of the Ministry of Education, Culture, Sports, Science, and Technology (MEXT) of Japan. The work was supported by the KAKUSHIN Program and KAKENHI, Grant-in-Aid for Scientific Research (A) provided by MEXT.

\section{References}

Allen, R. G., L. S. Pereira, D. Raes, and M. Smith, 1998: Crop evapotranspiration: guidelines for computing crop water requirements. FAO Irrigation and drainage paper 56, FAO_Food and Agriculture Organization of the United Nations Rome, http:// www.fao.org/docrep/X0490E/x0490e00.htm.

Doll, P., and J. Zhang, 2010: Impact of climate change on freshwater ecosystems: a global-scale analysis of ecologically relevant river flow alterations. $\mathrm{Hy}$ drol. Earth Syst. Sci., 14, 783-799.

Hargreaves, G. H., and Z. A. Samani, 1985: Reference crop evapotranspiration from temperature. Appl. Eng. Agric., 1 (2), 96-99.

Hargreaves, G. H., and R. G. Allen, 2003: History and evaluation of Hargreaves evapotranspiration equation. J. Irrig. Drain. Eng., 129, 53-63. 
Hirabayashi, Y., S. Kanae, S. Emori, T. Oki, and M. Kimoto, 2008: Global projections of changing risks of floods and droughts in a changing climate. $\mathrm{Hy}$ drol. Sci. J., 53 (4), 754-772.

IPCC, 2007a: Climate change 2007: The physical science basis. Contribution of Working Group I to the fourth assessment report of the intergovernmental panel on climate change. Solomon S., D. Qin, M. Manning, Z. Chen, M. Marquis, K. B. Averyt, M. Tignor, and H. L. Miller (Eds.). Cambridge University Press, Cambridge, 996 pp.

IPCC, 2007b: Climate change 2007: Impacts, adaptation, and vulnerability. Contribution of Working Group II to the fourth assessment report of the intergovernmental panel on climate change. M. L. Parry, O. F. Canziani, J. P. Palutikof, P. J. van der Linden, and C. E. Hanson (Eds.). Cambridge University Press, Cambridge, 976 pp.

Jenson, S. K., and J. O. Domingue, 1988: Extracting topographic structure from digital elevation data for geographic information system analysis. Photogrammetric Engineering and Remote Sensing, 54 (11), 1593-1600.

Kiem, A. S., H. Ishidaira, H. P. Hapuarachchi, M. C. Zhou, Y. Hirabayashi, and K. Takeuchi, 2008: Future hydroclimatology of the Mekong River basin simulated using the high-resolution Japan Meteorological Agency (JMA) AGCM. Hydrological Processes, 22, 1382-1394.

Kim, S., Y. Tachikawa, E. Nakakita, and K. Takara, 2009: Reconsideration of reservoir operations under climate change: case study with Yagisawa dam, Japan. Annual Journal of Hydraulic Eng., JSCE, 53, 115-120.

Kim, S., Y. Tachikawa, E. Nakakita, and K. Takara, 2010: Hydrologic evaluation on the AGCM20 output using observed river discharge data. Hydro. Res. Lett., 4, 35-39.
Kitoh, A., T. Ose, K. Kurihara, S. Kusunoki, M. Sugi, and KAKUSHIN Team-3 Modeling Group, 2009: Projection of changes in future weather extremes using super-high-resolution global and regional atmospheric models in the KAKUSHIN Program: Results of preliminary experiments. Hydro. Res. Lett., 3, 49-53.

Koontanakulvong, S., and W. Chaowiwat, 2011: GCM data comparison and its application to water disaster adaptation measures in Thailand. Technical Report, Water Resources System Research Unit, Faculty of Engineering, Chulalongkorn University, Thailand, 2011.

Kusunoki, S., R. Mizuta, and M. Matsueda, 2011: Future changes in the East Asian rain band projected by global atmospheric models with $20-\mathrm{km}$ and 60-km grid size. Clim. Dyn., doi: 10.1007/ s00382-011-1000-X.

Shuttleworth, W. J., 1993: Evaporation. In: Maidment D. R. (Ed.), Handbook of Hydrology, Chapter 4, McGraw-Hill, 4.18.

Pokhrel, Y., N. Hanasaki, S. Koirala, S. Kanae, and T. Oki, 2010: Extreme river discharge under present and future climate conditions using high-resolution climate model data. Annual Journal of Hydraulic Eng., JSCE, 54, 97-102.

Tachikawa, Y., S. Takino, Y. Fujioka, K. Yorozu, S. Kim, and M. Shiiba, 2011: Projection of river discharge of Japanese river basins under a climate change scenario (in Japanese). J. Japan Soc. of Civil Eng., B1 (Hydraulic Eng.), 67(1), 1-15.

Takara, K., and J. R. Stedinger, 1994: Recent Japanese contribution to frequency analysis and quantile lower bound estimator. In: Hipel K. W. (Ed.), Stochastic and Statistical Methods in Hydrology and Environmental Engineering, Kluwer Academic Publishers, 1, 217-234.

USGS, 2011: HydroSHED, http://hydrosheds.cr.usgs .gov/. 